\title{
Lactobacillus delbrueckii subsp. lactis DSM7290 pepG gene encodes a novel cysteine aminopeptidase
}

\author{
Jürgen R. Klein, Joachim Schick, Bernhard Henrich and Roland Plapp
}

Author for correspondence: Jürgen R. Klein. Tel: +49631 205 2347. Fax: +496312053799.

e-mail: jklein@rhrk.uni-kl.de

Abteilung Mikrobiologie der Universität, Postfach 3049, 67653 Kaiserslautern, Germany

\begin{abstract}
A number of Escherichia coli clones were isolated from a Lactobacillus delbrueckii subsp. lactis gene library capable of hydrolysing the chromogenic substrate Gly-Ala- $\beta$-naphthylamide (Gly-Ala- $\beta$ NA). Some of the recombinant plasmids carried by these clones have been shown to encode the cysteine aminopeptidase gene pepC. Nucleotide sequence analyses of the plasmid inserts of the remaining clones resulted in the identification of two adjacent ORFs encoding proteins exhibiting a high degree of similarity between themselves $(72.6 \%)$ and with PepC. One gene, designated pepG, was overexpressed in $E$. coli and the crude extracts obtained were shown to be peptidolytically active both against chromogenic substrates and peptides, and in a Salmonella typhimurium growth test. PepC and PepG activities were compared using chromogenic $\beta$ NA and p-nitroanilide substrates and leucine or proline-containing peptides were applied in growth experiments of recombinant Sal. typhimurium. The results indicate that the enzymes, although structurally related, have different substrate preferences. No enzyme activity could be ascribed to the second ORF (orfW), despite the production of a visible protein using a T7 RNA polymerase system. Primer extension analysis, using mRNA isolated from $L$ b. delbrueckii subsp. lactis DSM7290 did establish that orfW was transcribed.
\end{abstract}

Keywords: Lactobacillus delbrueckii subsp. lactis, cysteine aminopeptidases, gene duplication

\section{INTRODUCTION}

Lactic acid bacteria are used as starter strains for the fermentation of a large range of food products. The thermophilic lactobacilli are among the main representatives used in industrial fermentations of hard cheese and yoghurt. They are extremely fastidious for a number of nutrients and milk is not an optimal growth medium for them. The growth rate of lactobacilli in milk depends on the production of proteolytic and peptidolytic enzymes, which together with respective peptide and amino acid transport systems co-ordinately act to use casein as a source for essential amino acids. Breakdown of casein and casein-derived peptides during ripening produces the typical texture and flavour of cheese. The proteolytic activity determines the rate and extent of the

Abbreviations: $p N A$, $p$-nitroanilide; $\beta N A, \beta$-naphthylamide.

The EMBL accession number for the nucleotide sequence reported in this paper is $\mathrm{Z71782}$. fermentation process. The manufacture as well as the quality of dairy products crucially depends on the properties of the starter organisms. A desire to understand better the proteolytic systems involved has led several research groups to study lactic acid bacteria (Pritchard \& Coolbear, 1993), particularly Lactococcus lactis (Poolman et al., 1995; Kok \& De Vos, 1994). Members of the genus Lactobacillus have also been investigated and genes involved in proteolysis isolated and characterized (Christensen et al., 1995; Dudley et al., 1996; Gilbert et al., 1996; Klein et al., 1996; Stucky et al., 1995a, b; Vesanto et al., 1995; and references therein).

We have previously characterized several genes of the proteolytic system of Lactobacillus delbrueckii subsp. lactis DSM7290, a strain originally isolated from Emmentaler cheese (Klein et al., 1996). In our recent screening for new peptidase genes in the multiple peptidase-deficient Escherichia coli strain CM89 we used the chromogenic substrate Gly-Ala- $\beta$-naphthyl- 
amide (Gly-Ala- $\beta$ NA), which is not cleaved by any of the previously cloned peptidases of DSM7290. This allowed the isolation of clones with the respective hydrolytic activity. Two of the recombinant plasmids obtained were found to carry the cysteine aminopeptidase gene ( $p e p C$ ), which was subsequently sequenced (Klein et al., 1994). This study describes the identification of two further genes, one of which, pepG, encodes a functionally active cysteine protease.

\section{METHODS}

Bacterial strains, plasmids and growth conditions. The bacterial strains and plasmids used are listed in Table 1. E. coli was grown at $37^{\circ} \mathrm{C}$ in Luria-Bertani (LB) medium (Sambrook et al., 1989), strain CM89 in LB supplemented with $100 \mu \mathrm{g}$ thymidine $\mathrm{ml}^{-1}$ and $L b$. delbrueckii subsp. lactis in MRS (De Man et al., 1960) at $37^{\circ} \mathrm{C}$. The ability of Salmonella typhimurium TN1547 transformed with plasmids pJKG8 and pJKC4, to utilize Leu- and Pro-containing peptides as amino acid sources was tested by placing a few peptide crystals (Bachem) on the surface of a minimal glucose plate inoculated with the strain, as described by Carter \& Miller (1984). Ampicillin or kanamycin were added when appropriate to give final concentrations of 200 and $40 \mu \mathrm{g} \mathrm{ml}^{-1}$, respectively.

Transformations. E. coli and Sal. typhimurium were transformed by electroporation using a Bio-Rad Gene Pulser as described by Dower et al. (1988) and O'Callaghan \& Charbit (1990).

Recombinant DNA techniques. Restriction enzymes and other nucleic-acid-modifying enzymes were used as recommended by the manufacturers and molecular cloning techniques were performed essentially as described by Sambrook et al. (1989). Isolation of chromosomal DNA from $L b$. delbrueckii subsp. lactis DSM7290 and preparation of a plasmid library in the low-copy-number vector pLG339 (Stoker et al., 1982) was performed as described previously (Klein et al., 1993). Primer extension of mRNA was performed as described previously (Matern et al., 1994) using oligonucleotides complementary to coding regions of orfW $\left(5^{\prime}\right.$ GAGCCCGCTGCGTCTGGCGGCCCGAG $3^{\prime}$; nt 550-575) and pepG (5' CATTGTAGGAAGCTTCCAGAACACCGC 3'; nt 1934-1960).

Cloning of the $\mathbf{L b}$. delbrueckii subsp. lactis orfW and pepG genes, plasmid constructions and DNA sequencing. The genomic library of $\mathrm{Lb}$. delbrueckii subsp. lactis DSM7290 (Klein et al., 1993) was used to transform E. coli strain CM89. Transformants with Gly-Ala- $\beta$ NA-cleaving activity were identified by a colorimetric plate assay as described previously (Klein et al., 1993). Isolated plasmids and plasmid constructions are illustrated in Fig. 1. DNA sequence determination of the chromosomal inserts of plasmid pJKG4 was initiated with synthetic oligonucleotide primers derived from the known sequence of the vector used. Further sequencing of pJKG4 and sequencing of the inserts of pJKG6 and pJKG2 was done by a primer-walking strategy with oligonucleotides synthesized on an Applied Biosystems Model 392 DNA/RNA synthesizer. The nucleotide sequence was established for both strands using the T7 DNA polymerase sequencing kit (Sequenase 2.0; USB), which is based on the dideoxynucleotide chain-termination method (Sanger et al., 1977) in the presence of $\left[{ }^{35} \mathrm{~S}\right] \mathrm{dATP} \alpha \mathrm{S}(\mathrm{ICN})$ with double-stranded plasmid DNA purified by NUCLEOBOND AX100 columns (MachereyNagel) as template. For computer-assisted DNA and amino acid sequence analyses, MICROGENIE (Beckman), PCGENE (IntelliGenetics), and HUSAR (GENIUSnet) software was used.

Expression of orfW in vitro and under control of the $\mathrm{T7}$ promoter. In vitro expression of plasmid DNA (pJKW1) was performed with a cell-free coupled transcription/translation system derived from $E$. coli (Amersham), according to the manufacturer's protocol. In vivo expression was carried out using E. coli PS1 as described by Sankar et al. (1993) with the modifications that vector pWSK129 (Wang \& Kushner, 1991) was applied and labelling with ${ }^{35} \mathrm{~S}$-Met was omitted. LB

Table 1. Bacterial strains and plasmids

\begin{tabular}{|c|c|c|c|}
\hline Strain & \multicolumn{2}{|c|}{ Genotype, relevant features } & Reference \\
\hline $\begin{array}{l}\text { Lb. delbrueckii subsp. lactis } \\
\text { DSM7290 }\end{array}$ & \multicolumn{2}{|l|}{ Source of plasmid library } & Klein et al. (1993) \\
\hline E. coli K-12 CM89 & \multicolumn{2}{|c|}{$\begin{array}{l}\mathrm{F}^{-} \text {leu-9 } \Delta(p r o A B \text { pepD) met thyA pepN102 pepA11 } \\
\text { pepB1 pepQ10 }\end{array}$} & Miller \& Schwartz (1978) \\
\hline E. coli B PS1 & \multicolumn{2}{|c|}{$\mathrm{F}^{-}$bsdS lacUV5::T7 gene 1 gyrA srl-300::Tn 10 recA1 } & Sankar et al. (1993) \\
\hline Sal. typhimurium TN1547 & \multicolumn{2}{|c|}{$\begin{array}{l}\text { leuBCD485 pepN90 pepA16 pepB11 supQ302 } \triangle \text { (proAB } \\
\text { pepD) pepP1 pepQ1 pepT1 pepE1 }\end{array}$} & Carter \& Miller (1984) \\
\hline Plasmid* & Relevant features $\dagger$ & Vector & Reference \\
\hline pLG339 & $\mathrm{Tc}^{\mathrm{r}} \mathrm{Km}^{\mathrm{r}}$ & & Stoker et al. (1982) \\
\hline pWSK129 & $\mathrm{Km}^{\mathrm{r}} \mathrm{p} \mathrm{T7}$ & & Wang \& Kushner (1991) \\
\hline pJKG2 & $\mathrm{Km}^{\mathrm{r}}$ orfW pepG & pLG339 & This study \\
\hline pJKG4, pJKG6, pJKG8 & $\mathrm{Km}^{\mathrm{r}} \Delta o r f W$ pepG & pLG339 & This study \\
\hline pJKW1 & $\mathrm{Km}^{\mathrm{r}}$ orfW & pLG339 & This study \\
\hline pJKW2 & $\mathrm{Km}^{\mathrm{r}}$ orfW & pWSK129 & This study \\
\hline pJKC4 & $\mathrm{Km}^{\mathrm{r}}$ pepC & pLG339 & Klein et al. (1994) \\
\hline
\end{tabular}

"All listed plasmids are derivatives containing the low-copy-number replicon pSC105.

$\dagger \mathrm{Km}$, kanamycin; $\mathrm{Tc}$, tetracycline. 


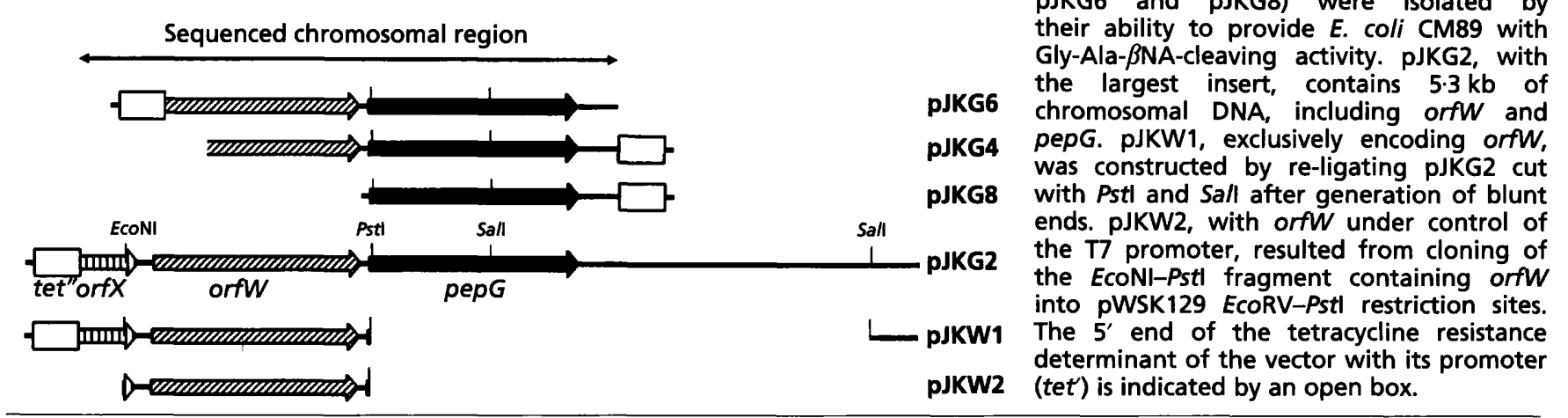

Fig. 1. Insert DNA of gene bank plasmids and subcloning of orfW. The initially isolated gene bank plasmids (pJKG2, pJKG4, pJKG6 and pJKG8) were isolated by their ability to provide $E$. coli CM89 with Gly-Ala- $\beta$ NA-cleaving activity. pJKG2, with the largest insert, contains $5.3 \mathrm{~kb}$ of chromosomal DNA, including orfW and was constructed by re-ligating PJKG2 cut with Pstl and Sall after generation of blunt ends. pJKW2, with orfw under control of the $\mathrm{T7}$ promoter, resulted from cloning of the EcoNI-Pstl fragment containing orfW into PWSK129 EcoRV-Pstl restriction sites. pJKW2 (tet') is indicated by an open box.

(300 ml) was inoculated with $1 / 100$ vol. of a PS1(pJKW2) overnight culture and incubated at $37^{\circ} \mathrm{C}$ until an $\mathrm{OD}_{600}$ of 0.5 was reached. T7 RNA polymerase was induced with IPTG $(0.5 \mathrm{mM}$ final concentration) and over a time course $(0,35,90$, $165,210$ and $420 \mathrm{~min}) 30 \mathrm{ml}$ aliquots were centrifuged and cell extracts prepared by ultrasonication of the bacteria, essentially as described previously (Klein et al., 1993). Inhibition of E. coli RNA polymerase by rifampicin was omitted.

Preparation of cell-free extracts and gel electrophoresis. Cell-free extracts from overnight cultures of $E$. coli were prepared as described previously (Klein et al., 1993). Preparations contained approximately $50 \mathrm{mg}$ protein $\mathrm{ml}^{-1}$ as determined by the Lowry method. Crude extracts were analysed by SDS-PAGE $(12.5 \%$ acrylamide) using the discontinuous buffer system of Laemmli (1970) and staining with Coomassie Blue, according to Weber \& Osborn (1969). The content of PepG protein in extracts was determined by video densitometry (Cybertech CS1, Image Documentation System) with Coomassie-stained SDS gels calibrated with bovine serum albumin.

Assay of peptidase activity, measurements of $\mathrm{pH}$ and temperature influences and effects of various chemical reagents. Peptidase $G$ was assayed in $0.4 \mathrm{ml}$ reaction vols by incubating crude extracts of $E$. coli CM89(pJKG8) at $37^{\circ} \mathrm{C}$ in the presence of $10 \mathrm{mM}$ Bis-Tris, $\mathrm{pH} 7 \cdot 0$, and $1 \mathrm{mM}$ Ala-Ala-pnitroanilide (Ala-Ala- $p$ NA) (Bachem) as substrate. After $30 \mathrm{~min}$, samples were heated at $90^{\circ} \mathrm{C}$ for $5 \mathrm{~min}$. The release of $p$-nitroaniline was determined at $405 \mathrm{~nm}$ in a LKB Ultrospec plus spectrophotometer. PepC activity was determined using CM89(pJKC4) extracts and Ala-pNA as substrate.

The effect of temperature on aminopeptidase activity was determined using Ala- $p$ NA (for PepC) or Ala-Ala- $p$ NA (for PepG) as a substrate in the range $5-70^{\circ} \mathrm{C}$. The reaction mixture was pre-incubated for $10 \mathrm{~min}$ at different temperatures before the addition of the substrate.

The effect of $\mathrm{pH}$ on aminopeptidase activities was determined in the range $\mathrm{pH} 4-10$ using a polybuffer composed of $200 \mathrm{mM}$ each of malic acid, MES, HEPES and boric acid adjusted to the appropriate $\mathrm{pH}$ with $\mathrm{KOH}$. Prior to the addition of the substrate, the extracts were equilibrated in the respective buffer for $10 \mathrm{~min}$.

To study the mechanism of enzyme action, the inhibitors 3,4dichloroisocoumarin at a concentration of $100 \mu \mathrm{M}$, Pefa Block

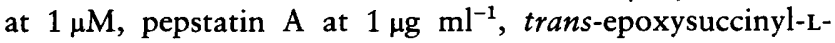

leucylamido-(4-guanidino)butane at $10 \mu \mathrm{M}$ and 1,10-phenanthroline or EDTA at $1 \mathrm{mM}$ were added to the extracts. The mixtures were incubated for $30 \mathrm{~min}$ at $37^{\circ} \mathrm{C}$, then the substrates (Ala-pNA for PepC, Ala-Ala- $p$ NA for PepG) were added. After further incubation for $30 \mathrm{~min}$, enzyme activity was measured spectrophotometrically as described above.

\section{RESULTS AND DISCUSSION}

\section{Identification of pepG and orfW}

Of the nine recombinant $E$. coli clones able to hydrolyse Ala- $\beta$ NA, two were found to possess a plasmid carrying pepC (Klein et al., 1994). The plasmids of the remaining clones were characterized by restriction analysis (Fig. 1) and the nucleotide sequence of one (pJKG4) was determined. A complete ORF was present which, on the basis of subsequent experimental data, was designated $p e p G$. Further sequencing of the $p e p G$ upstream region on plasmid pJKG6 identified an adjacent $5^{\prime}$-terminally truncated ORF, designated 'orf W, which showed marked similarity to pepG. Since the $5^{\prime}$ terminus of orfW was missing on all the other plasmids, we rescreened the gene bank for clones possessing Gly-Ala$\beta$ NA-cleaving activity. Restriction analysis identified a plasmid, designated pJKG2, which contained a chromosomal insert encoding the complete coding regions of orfW and pepG. For comparative studies we separated orfW by deleting the pepG-containing PstI-SalI fragment from pJKG2. We had already isolated a plasmid, pJKG8, which exclusively contained pepG in its insert (Fig. 1).

\section{Sequence analysis}

Through analysis of the inserts of plasmids pJKG2, pJKG4 and pJKG6, and pJKG8 (Fig. 1), the nucleotide sequence of a $3375 \mathrm{bp}$ region of the $L b$. delbrueckii subsp. lactis DSM7290 genome was determined (Fig. 2). In addition to orf $W$ and $p e p G$, this included a region 470 nt upstream of orf $W$, encompassing a partial ORF ('orf $X$ ), and extending $225 \mathrm{nt}$ downstream of pepG.

The orf $W$ coding region $(55.6 \% \mathrm{G}+\mathrm{C})$ initiates with an AUG start codon at position 471 , preceded by a potential 


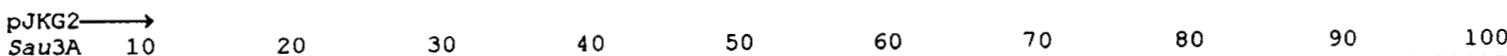
GATCACATGGGCGACTGGCTCGACAAATGGACAGCCACGCTTTCAGAAACATTTTGCAATCAGACGTTGCTGAAGATGAGCACGAATACACCGTCAAGAT $\begin{array}{clllllllllllllllllllllllllllllllll}S & H & G & R & L & A & R & Q & M & D & S & H & A & F & R & N & I & L & Q & S & D & V & A & E & D & E & H & E & Y & T & V & K & I\end{array}$ 'OrfX $\longrightarrow$

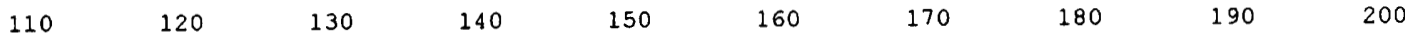
CGACGTGCCGGGGATGAGCAAGGAT GACATCCACCTCTCCTACACTGACGGGATTTTGACGATTTCCGCCCACCGCAGCACTTTCAAGGATGACAGCGAC

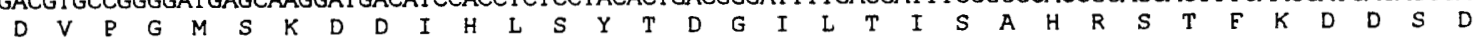

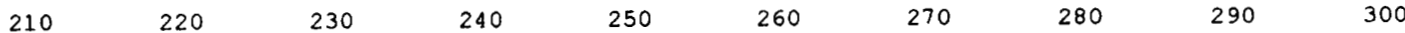
AAGAAGAAGAACCTCTTGCGCCAGGAACGCAGCGAAGGGTCAGTTTCCAGAAGCTTCAGCCTGCCGAACGTTGACAAGAAAGGCATTAGCGCCAAGCTTG

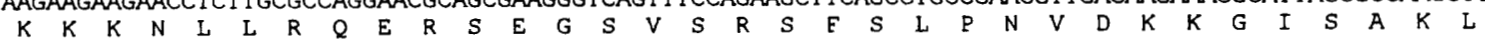

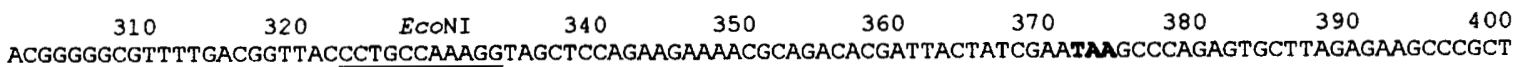

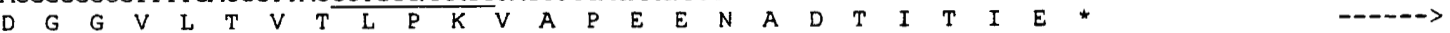

$410 \quad-35 \quad$ orfW promoter $\quad-10 \quad 450 \quad \longrightarrow$ mRNA $\quad 470 \quad 480 \quad 490 \quad 500$ ACGGCTTCTTTTTTIOCCCTCTTTAGCGTAAGATTATTCTATAATCATCTATT OCTAAGGGAGATTTTTCATGACACACGAATTAAGCCCCAGCTGCTC <--.--

Potential terminator

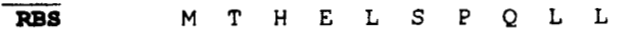

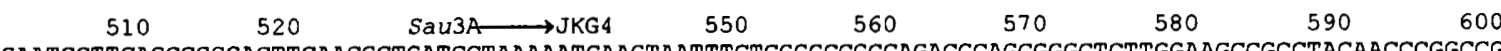
GAATCCTTCAGCCGGGACTTCAACGCTGATCCTAAAAATCAAGTAATTTCTCGGGCCGCCAGACGCAGCGGGCTCTTGGAAGCCGCCTACAACCCGGCCG $\begin{array}{llllllllllllllllllllllllllllllllllll}E & S & E & S & R & D & F & N & A & D & B & K & N & Q & V & I & S & R & A & A & R & R & S & G & L & L & E & A & A & Y & N & P & A\end{array}$

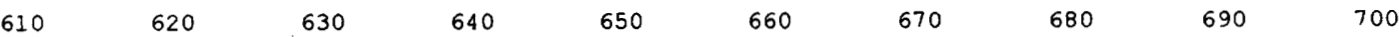
TCAGCCAGCGGCTGAACCGGACTTTTTCCATCGAGCTGGACACTGACAATGTCACCAACCAGCAGCAATCCGGCCGCTGCTGGCTCTTTTCAACCTTGAA $\begin{array}{lllllllllllllllllllllllllllllllllllll}V & S & Q & R & L & N & R & T & E & S & I & E & L & D & T & D & N & V & T & N & Q & Q & Q & S & G & R & C & W & L & F & S & T & L & N\end{array}$

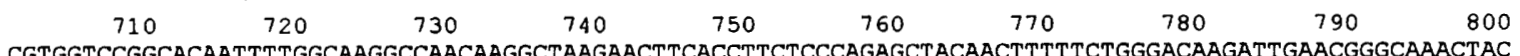

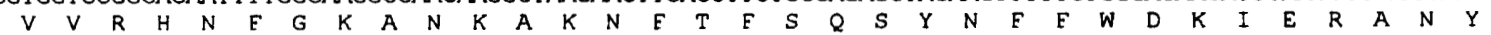

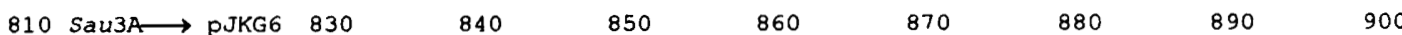
TTCTACGACCGGATCATTGCGACGGCTGACCGGCCTTTGACTGACCGGACAGTCCGCGGCTACTTTGACTGGTGCCAGACCGATGGCGGCCAGTGGCACA

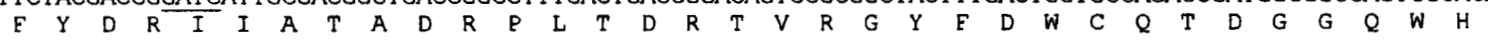

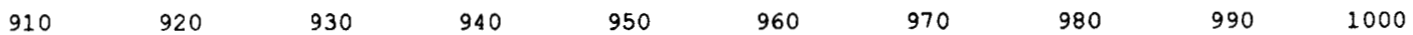
TGGCGGCTTCCCTCATCGCCAAATACGGGGTAGTGCCACGTTACGCCAT GCCGGAAAGCTTCAACAGCAACCACAGCCAGGCTTTGGACATGGTTTTGGC $\begin{array}{llllllllllllllllllllllllllllllllllll}M & A & A & S & L & I & A & K & Y & G & V & V & P & R & Y & A & M & P & E & S & E & N & S & N & H & S & Q & A & L & D & M & V & L & A\end{array}$

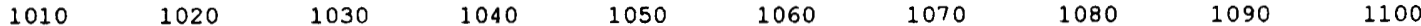
CGACAAGGAAAGAAAAGACGCCTTGACCCTGCGCCGGCTGGCGCAAGCAGACGACCAGGAAAAGCTGGAGGCGGCCCGGACTGACTTTTTAAGCCAGATC

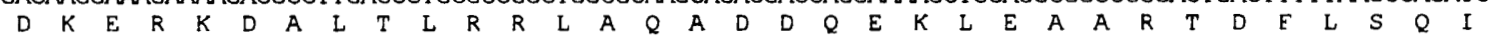

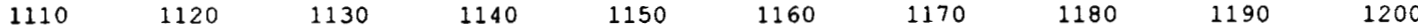
TACCGGATCATGGCTACGGCCTTGGGTGAACCGCCGAAGACTTTTGACCTGGAATTCAGAGACGACGACAAGAACTACCACTTGGACAAGGGCTTGACTC $\begin{array}{lllllllllllllllllllllllllllllllllll}Y & R & I & M & A & T & A & L & G & E & P & P & K & T & F & D & L & E & E & R & D & D & D & K & N & Y & H & L & D & K & G & L & T\end{array}$

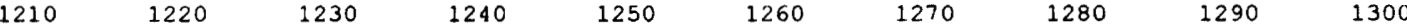
CGGTCCAGTTCTACAAAAAGTACTGCGCGACCGATCTGGACGACTATGTGGTTTTGGCTAATGCCCCAGACCATGAAATGAACCGGGTCTTGCACCTGGG

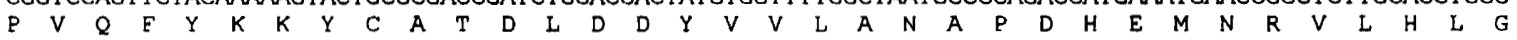
$\begin{array}{lllllllll}1310 & 1320 & 1330 & 1340 & 1350 & 1360 & 1370 & 1380 & 1390\end{array}$ CTTTGAAGACAACATTAAGGGCGGCTACCCTAACCTCTTCATCAACGTGCCGATGGAATATCTGGAAGACGCGGCGATTGCCCAGCTGAAGGACGGGGAA $\begin{array}{lllllllllllllllllllllllllllllllllllll} & E & E & D & N & I & K & G & G & Y & P & N & L & E & I & N & V & P & M & E & Y & L & E & D & A & A & I & A & Q & L & K & D & G & E\end{array}$

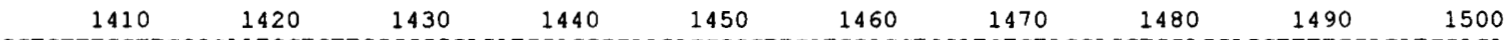
GCTGTTTGGTTCGGCAATGCTGTTGGCCGGCAGATGGACCGCAAGACCGGCTTCATGGACCTGGATCTCTACCAGCTGGACCAGCTTTTGGACATCGACA $\begin{array}{llllllllllllllllllllllllllllllllllll}A & V & W & F & G & N & A & V & G & R & Q & M & D & R & K & T & G & F & M & D & L & D & L & Y & Q & L & D & Q & L & L & D & I & D\end{array}$

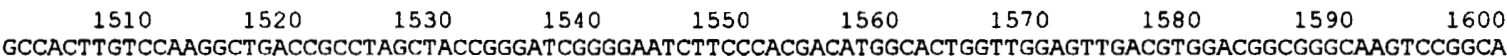
$\begin{array}{llllllllllllllllllllllllllllllllllllll}S & H & \text { L } & S & \text { K } & A & D & R & \text { L } & A & T & G & \text { I } & G & E & S & S & H & D & M & A & \text { L } & V & G & V & D & V & D & G & G & Q & V & R & Q\end{array}$

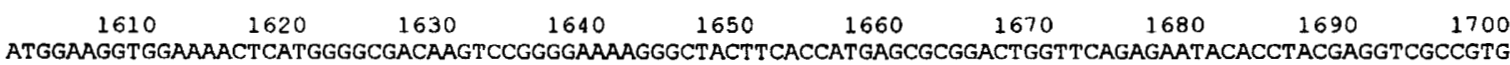

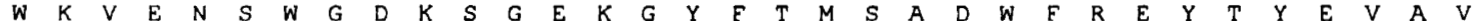

Fig. 2. For legend see facing page.

ribosome binding site (RBS) (GGAG, -7 bp; Shine $\&$ Dalgarno, 1974) and terminates with a translational UAA stop codon at position 1782 . This gene is followed by the pep $G$ coding region $(53.7 \% \mathrm{G}+\mathrm{C})$ which is also preceded by a typical RBS (AGGAG, $-8 \mathrm{bp}$ ), starts with AUG at nt 1837 and terminates with UAA at nt 3150.
The transcriptional starting points of orf $W$ and pepG were determined by primer extension experiments (Matern et al., 1994) and the upstream regions were searched for promoter motifs. The predicted -35 and -10 regions of pep $G$ are separated by $17 \mathrm{nt}$, which is in agreement with the consensus spacing, with two nucleo- 
$\begin{array}{lllllll}1710 & 1720 & 1730 & 1740 & \text { Sau3A—pJKG8 } & \mathbf{- 3 5} \text { pepG promoter }\end{array}$ CAAAAGAAGCACGTGCCGGCTGAAATCCTGGACCTGCTCAAGAACCAGCCGATCGAACTTGATCCTTGGGATTCCTTAATTTAAGCAGGTATGTTAACAT

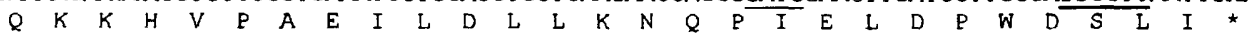

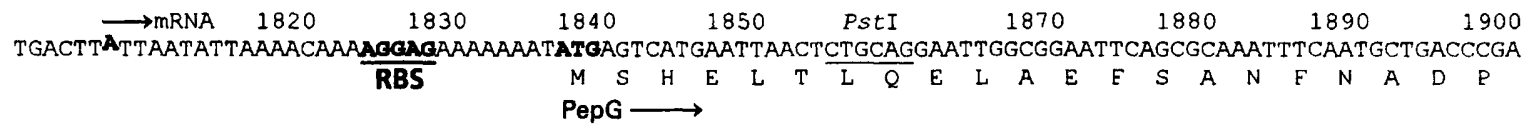

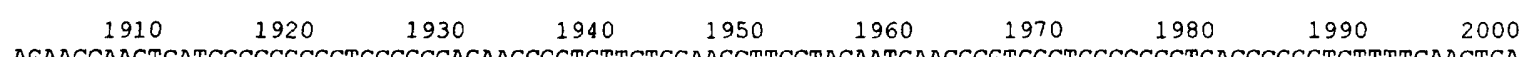
AGAACCAAGTCATCGCCCGCGCTGCCGCCAGAAGCGGTGTTCTGGAAGCTTCCTACAATGAACGCGTGGCTGGCCGCCTGACCCGGGTCTTTTCAACTGA

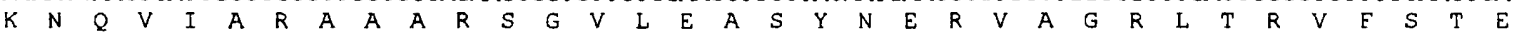
$\begin{array}{llllllll}2010 & 2020 & 2030 & 2040 & 2050 & 2060 & 2070 & 2080\end{array}$ ATTGCCAACGGACAACGT CACCAACCAAAAGCAGTCCGGCCGCTGCTGGCTTTTCTCAACCTTGAACGTCTTGCGCCACGACTTCGGCGCCAAGCATAAG

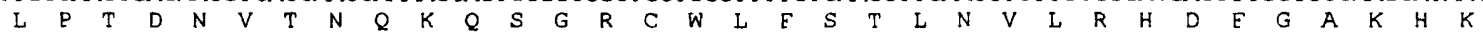
$\begin{array}{llllllll}2110 & 2120 & 2130 & 2140 & 2150 & 2160 & 2170 & 2180\end{array}$ GCCAAGAACTTTACCCTGTCCCAAAGCTACAACTTCTTCTGGGACAAGCTAGAAAGAGCCAACCTTTTCTATGAAAAAGTGATCGAAACCGCTGATAAAC

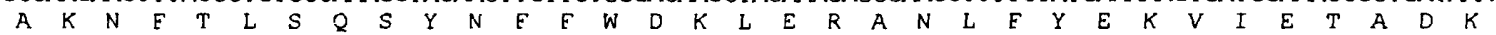
$\begin{array}{llllllll}2210 & 2220 & 2230 & 2240 & 2250 & 2260 & 2270 & 2280\end{array}$ CATTAGACGACCGGGAAGTCCGCAGCTACTTCGACTTCGCCGGCCACGACGGCGGCCAATGGCACATGGCCATCTCTTTGGTCAAGAAGTATGGTGTCGT

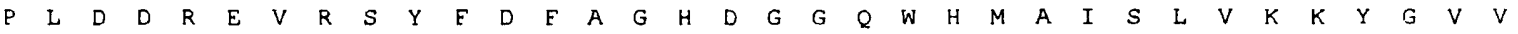
$\begin{array}{llllllll}2310 & 2320 & 2330 & 2340 & 2350 & 2360 & 2370 & 2380\end{array}$ GCCAAGCTACGTTATGCCTGAAAGCTTCAACACTTCCGCTACTAACGGTTTGGCCAGCGCCCTGGCTGACAAGGAAAGAAAAGACGCCCTGGCCTTGCGC

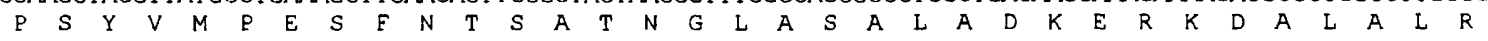
$\begin{array}{lllllllll}2410 & 2420 & 2430 & 2440 & 2450 & 2460 & 2470 & 2480\end{array}$ CGCCTGGCTCAAGCAGGTGACCAGGAAGGGCTGGAAAAGGCCCGCAAGACCTTCTTAAACGAAATCTACCGGATGGTTGCCATCGCCGTTGGTGAACCGC

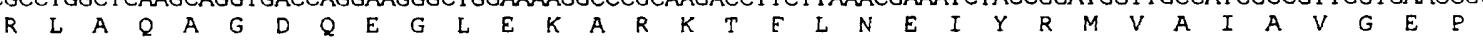
$\begin{array}{lllllllll}2510 & 2520 & 2530 & 2540 & 2550 & 2560 & 2570 & 2580 & 2590\end{array}$ CAAAGACTTTTGACCTGGAATACAGAGACGACGACAAGAACTACCACTTGGAAAAGAACTTGACCCCAGTCTCCTTCTTCAACAAGTACTTTGACGTCGA

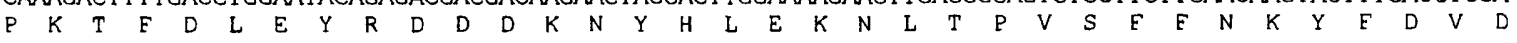
$\begin{array}{lllllllll}2610 & 2620 & 2630 & 2640 & 2650 & 2660 & 2670 & 2680 & 2690\end{array}$ CCTGGACGACTACGTGGTCTTGACCAACGCCCCAGACCACGAATACGGCAAGCTCTACCACCTGGGCGCTGAAGACAACGTTGAAGGCGGCAGCCCGATC

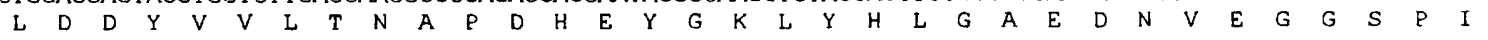
$\begin{array}{lllllllll}2710 & 2720 & 2730 & 2740 & 2750 & 2760 & 2770 & 2780 & 2790\end{array}$ CTCTTCTTGAACGTGCCGATGGAATACCTGGAGCAAACCGCTGTTGCCCAATTAAAGGACGGGGAAGCTGTCTGGTTCGGCAACGACGTCCTGCGGCAAA

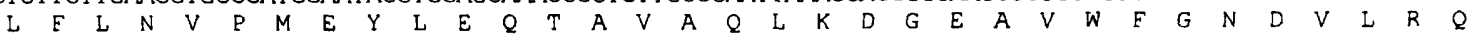
$\begin{array}{lllllllll}2810 & 2820 & 2830 & 2840 & 2850 & 2860 & 2870 & 2880 & 2890\end{array}$ TGGACCGCAAGACCGGCTACCTGGACACTGACCTCTACAAGCTGGAAGACCTCTTTGACGTTGACCTTAGCCTGTCCAAGGCTGACCGTCTGGCTACCGG $\begin{array}{llllllllllllllllllllllllllllllllllllllll}M & D & R & K & T & G & Y & L & D & T & D & L & Y & K & L & E & D & L & E & D & V & D & L & S & L & S & K & A & D & R & L & A & T & G\end{array}$ $\begin{array}{lllllllll}2910 & 2920 & 2930 & 2940 & 2950 & 2960 & 2970 & 2980 & 2990\end{array}$ CGCTGGTGAAGTTTCCCACGCCATGACCCTAGTCGGGGTTGATGAAGATAAGGGCGACATCCGCCAATGGAAGGTGGAAAACTCCTGGGGCGACAAGTCC

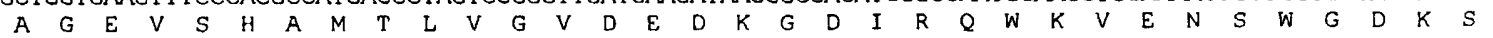

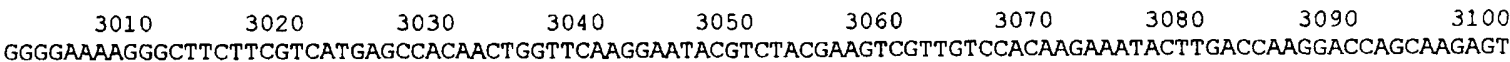

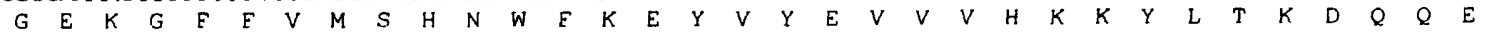

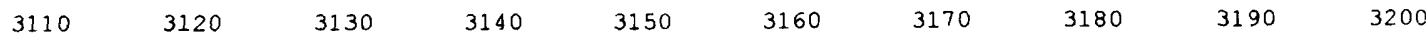
TGCTCTCTTCAACTCCTGTTGAACTTGCTCCTTGGGACTCATTAGCCTAATGGGTACGCTGATTATCGTCGGCTTGATTTCGCTCGTCATGCTGGGCCTG

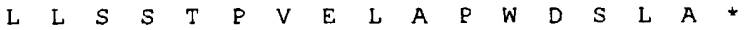

$\begin{array}{llllllll}3210 & 3220 & 3230 & 3240 & 3250 & 3260 & 3270 & 3280\end{array} 3290 \quad 3300$ GTCATCGCCGCCCTTCACCGGGATTAAGCACGAAAAACCGCTCAGTTCTCTAACAGAACTTGAGCGGTTTTTACTTTGGACTTAATCCTTGCTCTTAAAC Potential terminator

$\begin{array}{llllll}3310 & 3320 & 3330 & 3340 & 3350 & 3360\end{array}$

TGGTCGCCGGCTAAAGTCCGGTAGAACTCAGCGTGAGCCGCGTTGTAGTAAGGCACCAGCCAGAGGAAGCCGATC $\longleftarrow$ OJKG4; PJKG8 Sau3A

Fig. 2. Nucleotide and deduced amino acid sequences of the $L b$. delbrueckii subsp. lactis DSM7290 orfW and pepG genes and part of the preceding 'orfX. Relevant Sau3A restriction sites indicate the start points of the chromosomal inserts in recombinant plasmids. The restriction sites used for subcloning of orfW are indicated. The predicted -35 and -10 regions of the putative promoters are underlined. The starts of transcription, determined by primer extension, as well as the ribosome binding sites (RBS) are indicated. The inverted repeats of the potential $\rho$-independent terminators are denoted by facing arrows and the run of $T$ residues is marked by dots.

tides matching the -35 consensus hexamer and four matching the -10 hexamer. The putative orf $W$ promoter matches the -35 motif in four of the six nucleotides, while the -10 region is identical to the consensus. However, these putative -35 and -10 regions are separated by $20 \mathrm{nt}$, which might result in 


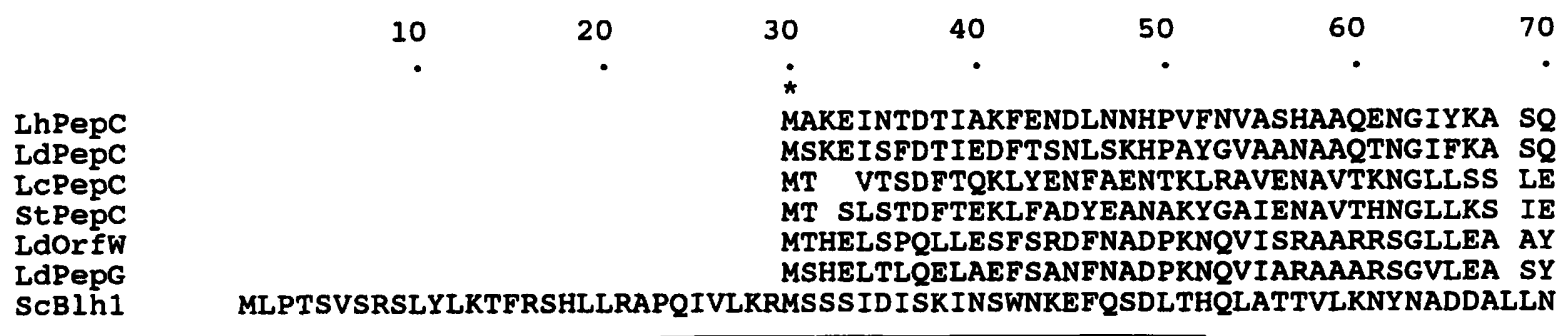

LhPepC LdPepC LcPepC StPepC LdOrfW LdPepG ScBIhI

LhPepc LdPepC LcPepC StPepC LdorfW LdPepG ScBlh1

LhPepC IdPepc LcPepC StPepC LdOrfW LdPepG ScBIh1

LhPepc LdPepC LcPepC stPepC LdOr $\mathrm{fW}$ LdPepG ScBIh1

LhPepC LdPepC LcPepC StPepC Ldor $f w$ LdPepG ScBlh1

LhPepc LdPepC LcPepC StPepC LdOrfW LdPepG ScBIhI

\begin{abstract}
*
NLQTKIDLDPIFSIEIDTGK STQSKVDLDPTFSVEIDTGS VRGSHAANLPEFSLDLTKDP TROSEVENDFVFSIDITKDE NPAVSQRLNRTFSIELDTDN NERVAGRLTRVFSTELPTDN

KTRLQKQDNRVENTVVSTDSTP
\end{abstract}

$* * * * * * * * * * *$
PANQKQSGRCWMFSALNTMRHPLQKKFK
VTNQKQSGRCWMFSALNTMRHSIQKEFK
VTNQRQSGRCWMFAALNTFRHKF INEFK
VSNQKASGRCWMFAALNTFRHKI ISDFK
VTNQQQSGRCWLFSTLNVRHNFGKANK
VTNQRQSGRCWLFSTLNVLRHDFGAKHK
VTNQRSSGRCWLFAATNQLRLNVLSELN

* $* * \quad * \star \star * *$ 作 TEDFEFSQAYTFFWDKYEKS LESFELSOAHTFFWDKYEKS AKNFTFSQSYNFFWDKIERA AKNFTLSQSYNFFWDKLERA LKEFELSQAYLFFYDKLEKA $\uparrow \uparrow$
70

\title{
* * $\quad$ * $\quad$ *
}

*** * * NWFFENVIATADKDLGDRKVSFLFATPQQDGGQWDMLCGI IEKYGIVPKSVYPE TANATNSSALNDTLN NFFFENVIGSADKPLGDRKVSFLFATPQSDGGQWDMLCGLIEKYGIVPKKVYPE TANSENSRALNDTIN NWFMEQI I GDVAMDDRRLKFLLQTPQQDGGQWDMMVAIFDKYGIVPKAVYPE SQASSSSRELNQYLN NWFLEOI I TADOE IGSRKVKFLLDTPOODGGOWDMVVSLFEKYGVVPKSVYPE SVASSNSRELNQYLN NYFYDRI IATADRPLTDRTVRGYFDWCQTDGGQWHMAASLIAKYGVVPRYAMPE SFNSNHSQALDMVLA NLFYEKVIETADKPLDDREVRSY FDFAGHDGGQWHMAI SLVKKYGVVPSYVMPE SFNTSATNGLASALA NYFLDQIVSSADQDIDSRLVQYLLAAPTEDGGQYSMFLNLVKKYGLIPKDLYGDLPYSTTASRKWNSLLT

\begin{abstract}
TVLRKDGLELR RLVNAGKSEDEVQARKEEMLNDVFRVLAISTCVPP TMLRKGGLELR ALVNEGKSTEEVEAHKAELLDAIFRMLATSLGLPP KLLRQDAEILR YTI EQDGDVQAVKEELLQEVFNFLAVTLGLPP KLLRQDAQILR DLIASGADQAAVQAKKEEFLQEIFNYLAMTLGLPP DKERKDALTLR RLA OADDQEKLEAARTDFLSOIYRIMATALGEPP DKERKDALALR RLA QAGDQEGLEKARKTFLNEIYRMVAIAVGEPP TKLREFAETLRTALKERSADDS I IVTLREQMQRE I FRLMSLFMD I PPVQPNEQFTWEYVDKDKKIHTIKS

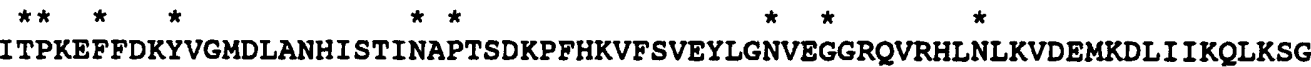
ITPQDFFKKYVGWDLENY I SVINGPTADKPYNKVF SVEYIGNVVGGRQVRHLNLELSKFKEL I INQLKQG TPKEFYNEYVGIDLNNYVSVINAPTADKPYNKSYTVEFLGNVVGGKEVKHLNVEMDRFKKLAIAQMOAG ITPRAFFEKYVGLKLSDYVSVINAPTADKPYGKSYTVEMLGNVVGAPSVRY INLPMDRFKELAIAQMKAG LTPVQFYKKYCATDLDDYVVLANAP DHEMNRVLHLGEEDNIKGGY PNLFINVPMEYLEDAAIAQLKDG LTPVSFFNKYFDVDLDDYVVITNAP DHEYGKLYHLGAEDNVEGGSPILFLNVPMEYLEOTAVAOLKDG TPLEFASKYAKLDPSTPVSLINDP RHPYGKLIKIDRLGNVLGGDAVIYLNVDNETLSKLVVKRLQNN
\end{abstract}

* ** * * * * * EVVWFGSNVVXDSERRAGLLDTNLYRRDQLFDVDFSMSKADKLDSGESMMDHAMVITGVDN GDGK PTK EVVWFGSDVSKGGDREAGLLDTKIYQRDQLFDYDFSMSKADRLDSGESMMNHAMVITAVDL VDDK PTK ETVWFGCDVGQESNRSAGLLTMDSYDFKSSLDIEFTQSKAGRLDYGESLMTHAMVLAGVDLDADGN STK ESVWFGSDVGQVSDRQKGILATNVYDFTASMDINWTODKAGRLDYSESLMTHAMVLTGVDLDADGK PIK EAVWFGNAVGRQMDRKTGFMDLDLYQLDQLLDIDSHLSKADRLATGIGESSHDMALVGVDV DGGQ VRQ EAVWFGNDVLRQMDRKTGYLDTDLYKLEDLFDVDLSLSKADRLATGAGEVSHAMTLVGVDE DKGD IRQ KAVFFGSHTPKFMDKKTGVMDIELWNY PAIGYNLPQQKASRIRYHESLMTHAMLITGCHVDETSKLPLR

$\uparrow$

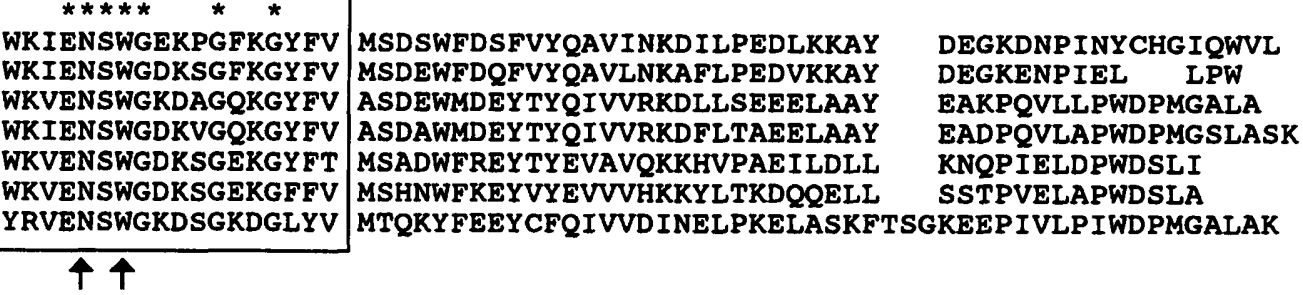

Fig. 3. Progressive alignment (TREE analysis) of the cysteine peptidases from Lb. delbrueckii subsp. lactis DSM7290 ( $L d P e p C=$ PepC [LDPEPC]; LdOrfW $=$ OrfW; LdPepG $=$ PepG) with the most similar cysteine aminopeptidases from $L b$. helveticus (LhPepC = PepC [LHPEPC]), LC. lactis (LCPepC = PepC [LLAPEPC]), S. thermophilus (StPepC = PepC [STPEPCGE]) and with the bleomycin hydrolase from Saccharomyces cerevisiae (SCBIh1 = BLH1 [BLH1_YEAST]. Database entry names are given in square brackets. Identical amino acids are marked by asterisks and the most conserved regions (which can be aligned with numerous cysteine aminopeptidases) are boxed. The amino acids glutamine (Q), cysteine (C), histidine (H), asparagine $(N)$ and tryptophan $(W)$, which are predicted to act in substrate binding and catalysis (Kamphuis et al., 1985), are indicated by arrows. 
(a)

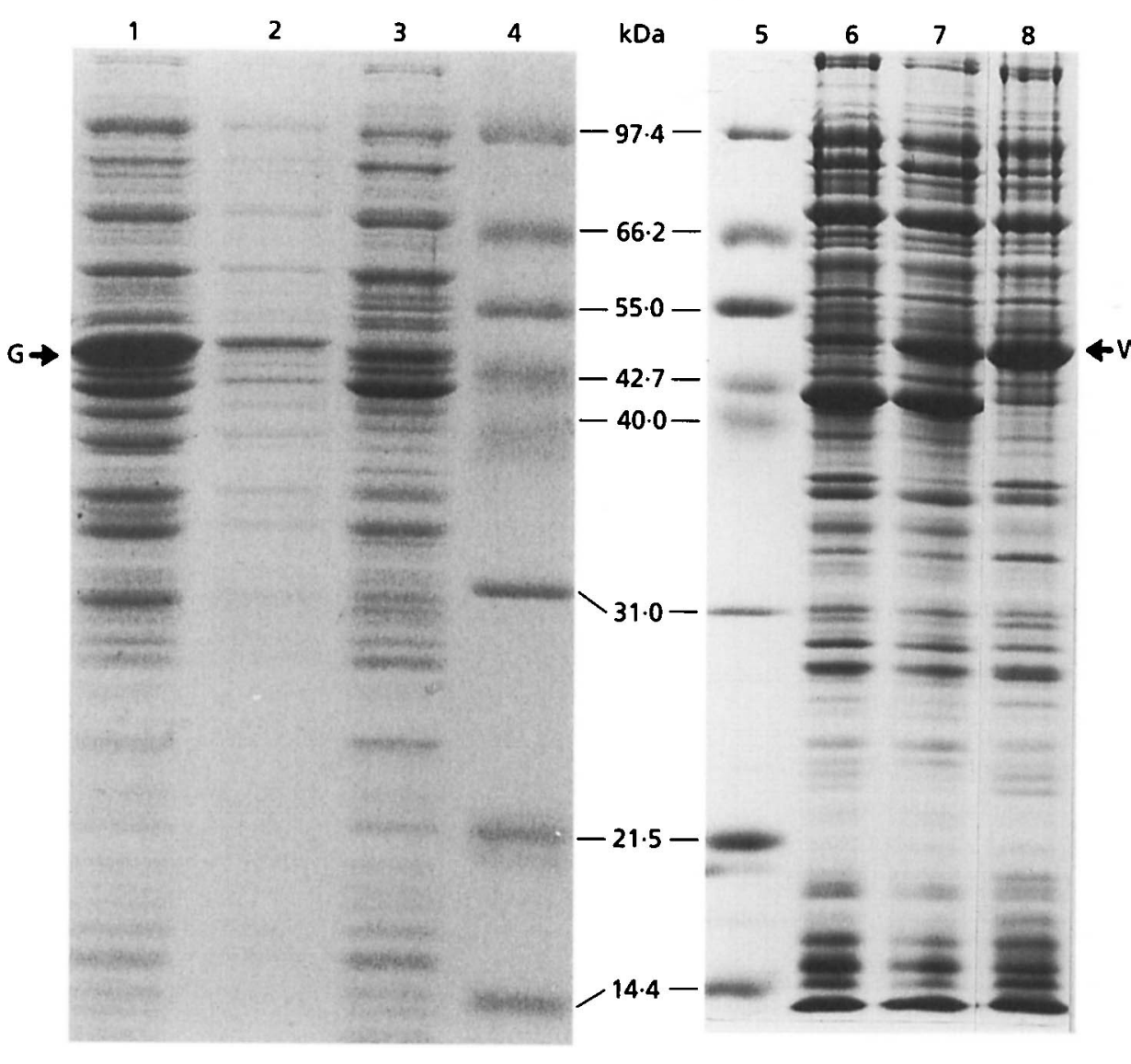

(c)

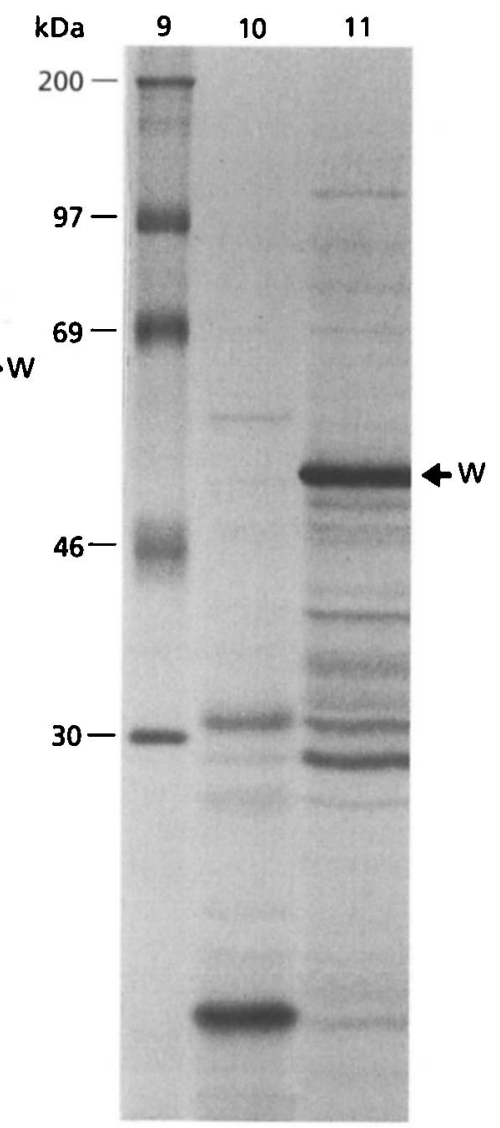

Fig. 4. Coomassie-stained SDS-polyacrylamide gels ( $12.5 \%$ acrylamide) showing PepG (a) and OrfW (b) expression. (a) Overexpression of PepG. Separation of crude extracts prepared from CM89(pJKG8) (lane 1; lane 2, 1/10 of the same extract as in lane 1) and CM89 (lane 3). PepG, identified by its predicted molecular mass of 49711 Da is indicated (G). (b) Overproduction of OrfW from plasmid pJKW2 in the T7 expression system. Extracts of PS1(pJKW2) were prepared 0 min (lane 6), 35 min (lane 7) and 420 min (lane 8) after induction of the T7 RNA polymerase with IPTG. The position of OrfW $(50 \mathrm{kDa})$ is indicated $(W)$. Lanes $4(\mathrm{a})$ and 5 (b), molecular mass markers. (c) Autoradiograph of a SDS-polyacrylamide gel (12\% acrylamide) showing plasmid-directed protein synthesis in a coupled in vitro transcription-translation system. ${ }^{35} \mathrm{~S}$ Met-labelled proteins synthesized in the presence of plasmids pLG339 (lane 10) or pJKW1 (lane 11), and ${ }^{14} \mathrm{C}$-methylated protein standards (lane 9) were separated. The main translation product of pJKW1, predicted to be OrfW (50 kDa), is indicated $(W)$.

inefficient gene expression. When searching for terminator structures, $\rho$-independent terminators ending in a run of $\mathrm{T}$ residues could be predicted for 'orf $X$ $\left(\Delta G=-41 \cdot 0 \mathrm{~kJ} \mathrm{~mol}^{-1}\right)$ and for pep $G(\Delta G=-112 \cdot 2 \mathrm{~kJ}$ $\left.\mathrm{mol}^{-1}\right)$. For orf W no such structure could be detected.

\section{Sequence similarities}

Comparative alignment of the orf $W$ and pepG coding regions demonstrated them to be highly conserved, exhibiting $72.6 \%$ nucleotide sequence identity. Screening of appropriate databases (EMBL, GenBank) revealed additional similarities. The highest degree of nucleotide sequence identity, as determined by FASTA analysis (Pearson \& Lipman, 1988), was with the prokaryotic cysteine aminopeptidase genes (pepC) from $L b$. delbrueckii subsp. lactis DSM7290, Lb. belveticus (Fernández et al., 1994; Vesanto et al., 1994), Streptococcus thermophilus (Chapot-Chartier et al., 1994), Lc. lactis
(Chapot-Chartier et al., 1993). Identities ranged from $59.5 \%$ to $53 \%$ throughout the whole coding regions.

When the deduced protein sequences were employed for database searches (SWISS-PROT, PIR, GenPep), sequence similarities with eukaryotic cysteine aminopeptidases were also noted. The yeast bleomycin hydrolase (Magdolen et al., 1993), a ubiquitous thiol proteinase with an as yet unknown function, displayed at least $33 \%$ identity with both the PepC and PepG thiol proteinases and OrfW. Minor, but significant similarities were also evident with several other thiol aminopeptidases. The latter homologies were mainly restricted to the two conserved sequence motifs of the cysteine protease family, one located at the $\mathrm{N}$ terminus and the second at the $\mathrm{C}$ terminus. The multiple sequence alignment shown in Fig. 3 summarizes these similarities. The calculated phylogenetic tree (not shown) indicates that OrfW and PepG are closely related. They build a 
separate branch besides the prokaryotic PepC cysteine aminopeptidases and it might be speculated that they are the result of a gene duplication.

\section{Gene expression in E. coli}

As had been observed for pepC (Klein et al., 1994), pepG was readily overexpressed in $E$. coli. In cell extracts of CM89(pJKG8), PepG constituted approximately $40 \%$ of the total soluble proteins of the cells (Fig. 4a). This efficient expression most probably results from Lactobacillus promoter structures preceding $p e p G$, since in the recombinant plasmid pJKG8 no vector promoters are located upstream of the structural gene. Overexpression of orfW, from recombinant E. coli CM89(pJKW1), did not result in a detectable protein product.

\section{In vitro transcription/translation of orfW}

To demonstrate that orf $W$ is preceded by a promoter which functions in E. coli, we performed a plasmiddirected in vitro transcription/translation with a coupled $E$. coli system. The detection of a ${ }^{35} \mathrm{~S}$-Metlabelled $50 \mathrm{kDa}$ protein (Fig. $4 \mathrm{c}$ ) indicates expression of orfW in $E$. coli. The presence of a promoter element, functional in $L b$. delbrueckii subsp. lactis, was also evident from the primer extension experiment.

\section{Overexpression of orfW in $E$. coli}

In contrast to other cloned peptidase genes (i. e. pepC, $p e p G, p e p I, p e p N, p e p V$ or pepX) (Klein et al., 1996) from $L b$. delbrueckii subsp. lactis, orf $W$ was not expressed with sufficient efficiency for its product to be visualized in Coomassie-stained polyacrylamide gels. Therefore, we placed orf W under the control of the T7 promoter by subcloning it as an EcoNI-PstI fragment into pWSK129 (Fig. 1). The resulting hybrid plasmid, pJKW2, was used to overexpress the gene in E. coli strain PS1. After induction of the system with IPTG, OrfW production could be monitored by the accumulation of a protein visible after staining of SDSpolyacrylamide gels with Coomassie Blue (Fig. 4b). The size of $50 \mathrm{kDa}$ for OrfW was in agreement with the value deduced from nucleotide sequence analysis $(50079 \mathrm{Da})$.

\section{Partial characterization of enzyme activities}

For a preliminary characterization of the two thiol aminopeptidases, PepC and PepG, we tested cleavage of $\beta$ NA and $p$ NA substrates by recombinant $E$. coli strains or cell-free extracts of such strains. In a second approach, the ability of the multiple-peptidase-deficient Sal. typhimurium TN1547, harbouring either pepC or $p e p G$, to utilize Leu- and Pro-containing peptides as amino acid sources was determined.

PepC and PepG activities could be easily distinguished by an enzymic plate assay using $\beta \mathrm{NA}$ substrates, as several of these are exclusively cleaved by one of the two peptidases (Table 2). A further distinction could be made when the relative peptidase activities of cell
Table 2. Substrate specificities of $L b$. delbrueckii subsp. lactis DSM7290 cysteine aminopeptidases PepC and PepG

Cleavage of chromogenic $\beta$ NA substrates was monitored in a plate assay using transformants of E. coli CM89 harbouring recombinant plasmids with inserted peptidase genes of strain DSM7290. The designations of the respective plasmids are given in parentheses. The relative cleavage rates for individual substrates are indicated by: + , fast; $+/-$, slow; - , not detectable).

\begin{tabular}{|lcc|}
\hline Peptidase & PepC (pJKC4) & PepG (pJKG8) \\
\hline Ala- $\beta$ NA & + & + \\
Ala-Ala- $\beta$ NA & + & - \\
Ala-Ala-Phe- $\beta$ NA & + & - \\
Arg- $\beta$ NA & + & - \\
Asp- $\beta$ NA & + & - \\
Cys(Bzl)- $\beta$ NA & + & - \\
Gly- $\beta$ NA & + & - \\
Gly-Ala- $\beta$ NA & + & + \\
Gly-Phe- $\beta$ NA & + & + \\
Gly-Pro- $\beta$ NA & - & - \\
Gly-Trp- $\beta$ NA & + & - \\
His- $\beta$ NA & $+/$ & - \\
Leu- $\beta$ NA & + & - \\
Leu-Gly- $\beta$ NA & + & + \\
Lys- $\beta$ NA & + & - \\
DL-Met- $\beta$ NA & + & - \\
Orn- $\beta$ NA & + & - \\
Phe- $\beta$ NA & + & - \\
Pro- $\beta$ NA & - & - \\
Ser- $\beta$ NA & + & - \\
Thr- $\beta$ NA & + & - \\
\hline
\end{tabular}

extracts for different $p$ NA-substrates (Pro-, Phe-, Tyr-, Leu-, Lys-, Gly-, Glu-, Ala-, Ala-Ala-pNA) were compared. The results (data not shown) confirm the broad specificity of PepC, which could degrade all tested $p$ NA substrates, with the exception of Pro-pNA, and exhibited a moderate preference for the substrate Ala$p N A$. In contrast, PepG could only degrade Ala- $p$ NA (55\% relative activity compared to PepC) and Ala-Ala$p$ NA $(100 \%$ relative activity).

The in vivo peptidolytic activities of PepC, PepG and OrfW on Leu- or Pro-containing peptides were further examined in growth experiments with Sal. typhimurium TN1547. The results (Table 3 ) indicate that PepC and PepG, although structurally related, have different substrate specificities. Whereas PepC has a broad substrate range for $\beta$ NA substrates, PepG was able to cleave more and different unmodified peptides. Further differences were observed when $\mathrm{pH}$ and temperature optima were determined (Fig. 5). The effect of temperature on aminopeptidase activity revealed the optimal temperature for PepC to be $37^{\circ} \mathrm{C}$, whereas PepG exhibited maximal activity between 50 and $55^{\circ} \mathrm{C}$.

The effect of $\mathrm{pH}$ on aminopeptidase activities was determined in the range $\mathrm{pH} 4-10$, and the optimum $\mathrm{pH}$ 
Table 3. Comparison of PepC and PepG activities

The utilization of Leu and Pro peptides by Sal. typhimurium TN1547(pJKG8) expressing pepG, and

TN1547(pJKC4) expressing pepC was determined by crystal tests. TN1547(pLG339) was used as a negative control. The ability, conferred by cloned peptidases, to grow on peptides as a Leu or Pro source is indicated by: +++ , good growth; ++ , growth; + , faint growth; - , no growth). Most of the peptides tested containing Pro (Ala-Ala-Pro-Ala, Ala-Ala-Pro-Ala-Ala, Ala-Pro, Ala-Pro-Ala, Ala-Pro-Gly, Ala-Pro-Phe, Arg-Pro, Gln-Pro, Glu-Pro, Gly-Gly-Pro, Gly-Pro, Gly-Pro-Ala, Gly-ProGly-Gly, Gly-Pro-Gly-Pro, Gly-Pro-Ile, Gly-Pro-Phe, Gly-Pro-Trp, His-Pro, His-Pro-Leu, His-ProVal, Ile-Pro, Ile-Pro-Ile, Leu-Ala-Pro, Leu-Gly-Pro, Leu-Pro, Lys-Pro, Lys-Pro-Arg, Lys-Pro-Val, Met-Pro, Met-Pro-Gly, Phe-Pro, Pro-Ala, Pro-Arg, Pro-Gln, Pro-Gly, Pro-Gly-Gly, Pro-His-Ala, Pro-His-Asp, Pro-His-Glu, Pro-His-Gly, Pro-His-Leu, Pro-His-Phe, Pro-His-Val, Pro-Ile, Pro-Leu, Pro-Lys, Pro-Met, Pro-Phe, Pro-Pro, Pro-Pro-Gly, Pro-Pro-Pro, Pro- $\beta$-Ala, Pro-Trp, Pro-Tyr, ProVal, Pro-Val-Asp, Pro-Val-Gly, Ser-Pro, $\beta$-Ala-Pro, Thr-Pro, Trp-Pro, Tyr-Pro, Val-Pro, Val-ProLeu) could not be cleaved by either peptidase. Phg, $\alpha$-aminophenylacetic acid.

\begin{tabular}{|c|c|c|c|c|c|}
\hline Peptide & $\begin{array}{l}\text { TN1547 } \\
\text { (pJKG8) }\end{array}$ & $\begin{array}{l}\text { TN1547 } \\
\text { (pJKC4) }\end{array}$ & Peptide & $\begin{array}{l}\text { TN1547 } \\
\text { (pJKG8) }\end{array}$ & $\begin{array}{r}\text { TN1547 } \\
\text { (pJKC4) }\end{array}$ \\
\hline Leu-Arg & - & - & Glu-Leu & - & - \\
\hline Leu-Gly & - & - & Gly-Leu & +++ & ++ \\
\hline Leu-His & - & - & His-Leu & - & - \\
\hline Leu-Ile & - & - & Ile-Leu & - & - \\
\hline Leu-Leu & ++ & - & D-Ala-Leu & - & - \\
\hline Leu-Met & ++ & - & D-Leu-Leu & - & - \\
\hline Leu-Phe & - & - & D-Phe-Leu & - & - \\
\hline Leu-Pro & - & - & D-Phg-Leu & - & - \\
\hline Leu-Ser & - & - & Leu-Ala-Pro & +++ & - \\
\hline Leu-Trp & - & - & Leu-Gly-Gly & - & - \\
\hline Leu-Tyr & - & - & Leu-Gly-Pro & ++ & - \\
\hline Leu-Val & - & ++ & Leu-Leu-Gly & ++ & - \\
\hline Leu-Phg & - & - & Leu-Leu-Leu & +++ & - \\
\hline Leu-D-Ala & - & - & Leu-Trp-Met & - & - \\
\hline Leu-D-Phg & - & - & Leu-Trp-Leu & - & - \\
\hline Leu- $\beta$-Ala & - & - & Leu-Tyr-Leu & - & - \\
\hline$\beta$-Ala-Leu & - & - & Gly-Leu-Tyr & + & - \\
\hline Lys-Leu & - & - & Gly-Leu-Gly & - & - \\
\hline Met-Leu & ++ & ++ & Val-Leu-Ser & - & - \\
\hline Phe-Leu & - & ++ & Ala-Val-Leu & +++ & - \\
\hline Pro-Leu & - & - & Gly-Gly-Leu & $++t$ & - \\
\hline Ser-Leu & +++ & - & His-Pro-Leu & - & - \\
\hline Thr-Leu & - & - & Pro-His-Leu & - & - \\
\hline Trp-Leu & - & - & Val-Pro-Leu & - & - \\
\hline Tyr-Leu & - & - & Leu-Trp-Met-Arg & - & - \\
\hline Val-Leu & - & - & Gly-Leu-Leu-Gly & ++ & - \\
\hline Ala-Leu & +++ & - & Met-Pro-Gly & - & + \\
\hline Arg-Leu & - & - & Gly-Gly-Pro & - & ++ \\
\hline Asp-Leu & - & - & & & \\
\hline
\end{tabular}

was determined to be 6.5 for PepC and $7 \cdot 0$ for PepG. PepG has a more narrow activity range between $\mathrm{pH} 6$ and 8 , whereas PepC displays a broader activity range between $\mathrm{pH} 4.5$ and 7.5 .

To study the mechanism of enzyme action, we exposed CM89(pJKC4) or CM89(pJKG8) cell extracts (containing overproduced $\mathrm{PepC}$ and $\mathrm{PepG}$, respectively) to a series of protease inhibitors. PepC and PepG were specifically inhibited by the cysteine protease inhibitor trans-epoxysuccinyl-L-leucylamido-(4-guanidino)butane to a final relative activity of $18 \%$
(PepC) and $20 \%$ (PepG), whereas the inhibitors 3,4dichloroisocoumarin, pepstatin A, Pefa block, 1,10phenanthroline or EDTA had no significant effect on enzyme activity. These results suggest that in accordance with the amino acid homologies observed, PepC and PepG can be classified as thiol proteases.

Even though OrfW sequences indicate a peptidase, no hydrolytic activity could be determined either in plate assays or crude extracts with chromogenic $\beta$ NA or $p$ NA substrates, nor in Sal. typhimurium growth tests. The genomic sequence which is so far available for DSM7290 


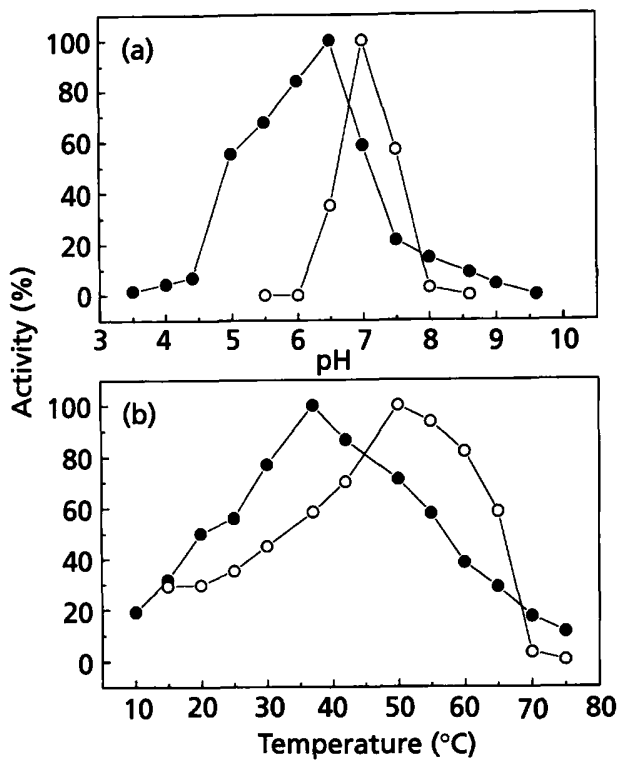

Fig. 5. Effect of pH (a) and temperature (b) on PepC (O) and PepG (O) activities.

indicates that the chromosome is very economically covered with genes, leaving only very small non-coding regions. This observation, together with the fact that orfW-specific mRNA could be isolated, indicates that orfW does indeed encode a product. The elucidation of the function and physiological importance of this protein awaits further experimentation.

\section{ACKNOWLEDGEMENTS}

This work was supported by grants from the Bundesministerium für Forschung und Technologie (0319281) and by the BRIDGE T-Project Biotechnology of Lactic Acid Bacteria grant of the EC (BIOT-CT91-0263 SSMA). We are grateful to Bernd Winkelmann for his excellent technical assistance.

\section{REFERENCES}

Carter, T. \& Miller, C. G. (1984). Aspartate specific peptidases in Salmonella typhimurium: mutants deficient in peptidase $\mathrm{E}$. J Bacteriol 159, 453-459.

Chapot-Chartier, M. P., Nardi, M., Chopin, M. C., Chopin, A. \& Gripon, J. C. (1993). Cloning of $p e p C$, a cysteine aminopeptidase from Lactococcus lactis subsp. cremoris AM2. Appl Environ Microbiol 59, 330-333.

Chapot-Chartier, M. P., Rul, F., Nardi, M. \& Gripon, J. C. (1994). Gene cloning and characterization of PepC, a cysteine aminopeptidase from Streptococcus thermophilus, with sequence similarity to the eucaryotic bleomycin hydrolase. Eur J Biochem 224, 497-506.

Christensen, J. E., Lin, V., Palva, V. \& Steele, J. L. (1995). Sequence analysis, distribution and expression of an aminopeptidase $\mathrm{N}$ encoding gene from Lactobacillus belveticus CNRZ32. Gene 164, 189-190.

De Man, J. C., Rogosa, M. \& Sharpe, M. E. (1960). A medium for the cultivation of Lactobacilli. J Appl Bacteriol 23, 130-135.

Dower, W. J., Miller, J. F. \& Ragsdale, C. W. (1988). High efficiency transformation of $E$. coli by high voltage electroporation. Nucleic Acids Res 16, 2127-2145.

Dudley, E. G., Husgen, A. C., He, W. \& Steele, J. L. (1996). Sequencing, distribution, and inactivation of the dipeptidase A gene (pepDA) from Lactobacillus helveticus CNRZ32. J Bacteriol 178, 701-704.

Fernández, L., Bhowmik, T. \& Steele, J. L. (1994). Characterization of the Lactobacillus helveticus CNRZ32 pepC gene. Appl Environ Microbiol 60, 333-336.

Gilbert, C., Atlan, D., Blanc, B., Portalier, R., Germond, J. E. G., Lapierre, L. \& Mollet, B. (1996). A new cell surface proteinase: sequencing and analysis of the prtB gene from Lactobacillus delbrueckii subsp. bulgaricus. J Bacteriol 178, 3059-3065.

Kamphuis, I. G., Drenth, J. \& Baker, E. N. (1985). Thiol proteases. Comparative studies based on the high-resolution structures of papain and actinidin, and on amino acid sequence information for cathepsins B and $\mathrm{H}$, and stem bromelain. J Mol Biol 182, 317-329.

Klein, J. R., Klein, U., Schad, M. \& Plapp, R. (1993). Cloning, DNA sequence analysis and partial characterization of pepN, a lysyl aminopeptidase from Lactobacillus delbrueckii subsp. lactis DSM7290. Eur J Biochem 217, 105-114.

Klein, J. R., Henrich, B. \& Plapp, R. (1994). Cloning and nucleotide sequence analysis of the Lactobacillus delbrueckii subsp. lactis DSM7290 cysteine aminopeptidase gene pepC. FEMS Microbiol Lett 124, 291-300.

Klein, J. R., Ulrich, C., Wegmann, U., Meyer-Barton, E., Plapp, R. \& Henrich, B. (1996). Molecular tools for the genetic modification of dairy lactobacilli. System Appl Microbiol 18, 493-503.

Kok, J. \& De Vos, W. (1994). The proteolytic system of lactic acid bacteria. In Genetics and Biotechnology of Lactic Acid Bacteria, pp. 169-210. Edited by M. J. Gasson \& W. M. De Vos. Glasgow: Blackie.

Laemmli, U. K. (1970). Cleavage of structural proteins during the assembly of the head of bacteriophage T4. Nature 227, 680-685.

Magdolen, U., Mueller, G., Magdolen, V. \& Bandlow, W. (1993). A yeast gene (BLH1) encodes a polypeptide with high homology to vertebrate bleomycin hydrolase, a family member of thiol proteases. Biochim Biophys Acta 1171, 299-303.

Matern, H. T., Klein, J. R., Henrich, B. \& Plapp, R. (1994). Determination and comparison of Lactobacillus delbrueckii subsp. lactis DSM7290 promoter sequences. FEMS Microbiol Lett 122, 121-128.

Miller, C. \& Schwartz, G. (1978). Peptidase deficient mutants of Escherichia coli. J Bacteriol 135, 603-611.

O'Callaghan, D. \& Charbit, A. (1990). High efficiency transformation of Salmonella typhimurium and Salmonella typhi by electroporation. Mol Gen Genet 223, 156-158.

Pearson, W. R. \& Lipman, D. J. (1988). Improved tools for biological sequence comparison. Proc Natl Acad Sci USA 85, 2444-2488.

Poolman, B., Kunji, E. R. S., Hagting, A., Juillard, v. \& Konings, W. L. (1995). The proteolytic pathway of Lactococcus lactis. $J$ Appl Bacteriol Symp Suppl 79, 65S-75S.

Pritchard, G. G. \& Coolbear, T. (1993). The physiology and biochemistry of the proteolytic system in lactic acid bacteria. FEMS Microbiol Rev 12, 179-206.

Sambrook, J., Fritsch, E. F. \& Maniatis, T. (1989). Molecular Cloning : a Laboratory Manual, 2nd edn. Cold Spring Harbor, NY: Cold Spring Harbor Laboratory. 
Sanger, F., Nicklen, S. \& Coulson, A. R. (1977). DNA sequencing with chain-terminating inhibitors. Proc Natl Acad Sci USA 74, 5463-5467.

Sankar, P., Hutton, M. E., VanBogelen, R. A., Clark, R. L. \& Neidhardt, F. C. (1993). Expression analysis of cloned chromosomal segments of Escherichia coli. J Bacteriol 175, 5145-5152 (author's correction J Bacteriol 176, 939).

Shine, J. \& Dalgarno, L. (1974). The 3'-terminal sequence of Escherichia coli $16 \mathrm{~S}$ ribosomal RNA : complementarity to nonsense triplets and ribosome binding sites. Proc Natl Acad Sci USA 71, 1342-1346.

Stoker, N. G., Fairweather, N. F. \& Spratt, B. G. (1982). Versatile low copy number plasmid vectors for cloning in Escherichia coli. Gene 18, 335-341.

Stucky, K., Hagting, A., Klein, J. R., Matern, H., Henrich, B., Konings, W. N. \& Plapp, R. (1995a). Cloning and characterization of $b r n Q$, a low affinity branched chain amino acid carrier gene from Lactobacillus delbrückii subsp. lactis DSM7290. Mol Gen Genet 249, 682-690.

Stucky, K., Klein, J. R., Schuller, A., Matern, H., Henrich, B. \& Plapp, R. (1995b). Cloning and DNA sequence analysis of $p e p Q$, a prolidase gene from Lactobacillus delbrueckii subsp. lactis DSM7290 and partial characterization of its product. Mol Gen Genet 247, 494-500.

Vesanto, E., Varmanen, P., Steele, J. L. \& Palva, A. (1994). Characterization and expression of the Lactobacillus helveticus pepC gene encoding a general aminopeptidase. Eur $\mathrm{J}$ Biochem 224, 991-997.

Vesanto, E., Savijoki, K., Rantanen, T., Steele, J. L. \& Palva, A. (1995). An X-Prolyl dipeptidyl aminopeptidase (pepX) gene from Lactobacillus helveticus. Microbiology 141, 3067-3075.

Wang, R. F. \& Kushner, S. R. (1991). Construction of versatile lowcopy-number vectors for cloning, sequencing and gene expression in Escherichia coli. Gene 100, 195-199.

Weber, K. \& Osborn, M. (1969). The reliability of molecular weight determinations by dodecyl sulphate-polyacrylamide gel electrophoresis. J Biol Chem 244, 4406-4412.

Received 1 May 1996; revised 19 August 1996; accepted 18 September 1996. 